\title{
Prophylaxis of Pain and Fractures within Feet in the Course of Osteoporosis: The Issue of Diagnosing
}

\author{
Aleksandra Bitenc-Jasiejko $\mathbb{D D}^{1}{ }^{1}$ Krzysztof Konior ${ }^{(D)},{ }^{2}$ Kinga Gonta $\left(\mathbb{D},{ }^{3}\right.$ \\ Magdalena Dulęba $\mathbb{D}^{3}{ }^{3}$ and Danuta Lietz-Kijak $\mathbb{D}^{1}$ \\ ${ }^{1}$ Department of Propaedeutic, Physical Diagnostics and Dental Physiotherapy, Pomeranian Medical University in Szczecin, \\ Szczecin, Poland \\ ${ }^{2}$ Doctoral Study Department of Propaedeutic, Physical Diagnostics and Dental Physiotherapy, \\ Pomeranian Medical University in Szczecin, Medical Center in Nowogard, Szczecin, Poland \\ ${ }^{3}$ College of Physiotherapy in Wroclaw, Ortogenic Rehabilitation and Podology Center in Wroclaw, Wroclaw, Poland
}

Correspondence should be addressed to Aleksandra Bitenc-Jasiejko; abj@posturologia.pl

Received 27 May 2020; Revised 10 September 2020; Accepted 10 November 2020; Published 29 November 2020

Academic Editor: Nan Jiang

Copyright (C) 2020 Aleksandra Bitenc-Jasiejko et al. This is an open access article distributed under the Creative Commons Attribution License, which permits unrestricted use, distribution, and reproduction in any medium, provided the original work is properly cited.

\begin{abstract}
Background. Considering the enormous risk of fractures in the course of osteoporosis in the area of the feet, an important aspect of prophylaxis is periodic and, in special cases, ongoing monitoring of defects and deformations as well as pressure distribution. The purpose of this article is to indicate the role of the examination of posture and pressure distribution during standing, postural balance, and gait, in the prevention of fatigue fractures in the course of osteoporosis, based on the literature review and examples of patients. Methods. The manuscript consists of two parts; it has a review-analytical character. The first part reviews the literature. The data were obtained using the MEDLINE (PubMed), as well as Cochrane and Embase databases. The database review was carried out focusing mainly on English-language publications, while taking into account the topicality of scientific and research works in the area of osteoporosis. The problem of multiaspects in the area of bone density was pointed out. Considering the above, in the second part, the authors analyzed 11 exemplary patients with osteoporosis, referring to the assessment of foot and lower limb defects using traditional posturological methods and including pedobarography to diagnostic procedures that are used in the assessment of pressure distribution, standing and moving, and an attempt to balance. Results. Analysis of the research and scientific literature proved the lack of unambiguous diagnostic procedures of the locomotor system recommended for the prevention of fatigue fractures in the course of osteoporosis. The main diagnostic recommendations are imaging tests (most often $\mathrm{X}$-ray), which are recommended in the case of specific clinical symptoms. The analysis of exemplary patients with osteoporosis showed numerous disorders in the distribution of pressure in the plantar part of the feet, which are related, among other things, with their individual defects and lower limbs. Conclusions. Detailed posture diagnostics and gait estimation, along with the analysis of pressure distribution within the feet are a very important aspect of the prevention of structural degradation and fatigue fractures within the feet. An important postulate for further research and scientific work is the elaboration of the procedures that will serve the preventive diagnostics of the locomotor system, aimed at early detection of threats of fatigue fractures.
\end{abstract}

\section{Introduction}

Osteoporosis is defined by the World Health Organization (WHO) as a reduction in the bone density index, which affects about $30 \%$ of women and $12 \%$ of men [1]. The issue of osteoporosis depends mainly on its differentiation, especially on the problem of bone osteomalacia, which has similar causes. Equally, in osteoporosis and osteomalacia, as well as in osteopenia, the most common element of these diseases is vitamin $\mathrm{D}$ deficiency, which leads to impaired phosphate and calcium concentrations. Vitamin D is produced inside the skin due to the influence of sunlight and supplied to the body with nourishment. Osteomalacia may also be caused by calcium and phosphate insufficiencies, for reasons unrelated 
to vitamin $\mathrm{D}$ (e.g., dietary deficiencies), lack of exposure to the sun, and malabsorption of vitamin $\mathrm{D}$ from the digestive tract or kidney and liver failure [2-5]. The analysis of osteomalacia usually detects decreased concentrations of calcium (may also be regular), phosphates, and the active form of vitamin D (25-OH-D), as well as an elevated concentration of alkaline phosphatase (ALP) [6]. In the definition of osteoporosis, WHO defines a reduced T-score of bone mineral density (BMD) as-2.5 (T-score $<-2.5$ ), diagnosed by X-ray imagining double emission (measured by dual-emission X-ray) [7-11]. Innovative medical engineering methods, the so-called Nanoindentation, indicate that there are significant contrasts in bone hardness in patients with osteoporosis, which affects their load resistance, deformation possibilities, and flexibility, while reducing microhardness in relation to the control group $[12,13]$.

Bone fragility and, as a result, fractures of the distal part of the foot, pelvic bone, sacral bone, head of the proximal tibial bone, and ribs may be a manifestation of osteomalacia, with a deficiency of vitamin D3 and an equally abnormal absorption of calcium ions and phosphates. These issues should be differentiated from fractures due to osteoporosis in which there is a rupture of the femoral neck, spine vertebrae, or spondylopathy by reducing bone mineral density, which are determined by densitometric examination. The fracture risk increases with age $[1,14,15]$.

Since 2001, osteoporosis has been ultimately defined as a disorder within the skeletal system, in which the risk of bone fracture increases, not only due to their reduced density, but also in the course of their fragility, which rises with age [16]. The lack of calcium or phosphates leads to decreased bone mineralisation, while a deficiency of vitamin $\mathrm{D}$ leads to weakened muscle receptors $[17,18]$. Hypophosphatemia is also induced by drug intake, for example, neutralising phosphates or diuretics, and also, although less frequently, by hereditary diseases and paraneoplastic production of phosphatonins. Additionally, this may be caused by conditions such as prostate cancer and bronchial cancer [19-22]. Therefore, it should be noted that osteoporosis is often a secondary disease in patients with chronic kidney, liver, and lung diseases, often resulting from ageing. Idiopathic osteoporosis also represents an essential aspect of considerations regarding the prevention of bone fractures and, as a consequence, the therapeutic challenge of an unknown etiological factor [23].

Osteoporosis is more common in women, and an additional factor determining its occurrence is menopause and the postmenopausal period (PMOP: postmenopausal osteoporosis), which is related to the impact of oestrogen on osteoclasts [24-29]. It has also been demonstrated that the number of pregnancies, age, and body mass index increase the risk of osteoporosis [30]. However, a much more important determinant of the fractures arising in the course of osteoporosis is advanced age [31]. Microlesions of tissues develop over time; nonetheless, in elderly women, fractures and overload cracks are more frequent $[15,32,33]$. It has been proven that age, BMI, and number of pregnancies are important determinants of the development of postmenopausal osteoporosis [34]. The fundamental and recurrent causes of decreased BMD index in the elderly, apart from systemic diseases and medications intake, include the improper supply of nutrients and a lack of physical activity [35-37].

Osteoporosis is a significant issue in diabetic patients, especially in terms of the prevention of diabetic foot syndrome and defragmentation, as well as bone fractures in the course of Charcot neuroosteoarthropathy. In the course of type I diabetes mellitus, a mild reduction of bone mineral density is noticed, whereas in type II diabetes mellitus, which is more frequent in older people, a regular or increased $\mathrm{BMD}$ index is observed. An enhanced risk of fractures in individuals with diabetes is associated with peripheral neuropathy and weakened muscle capacity, which in consequence affects local structural instability caused by hyperglycaemia, particularly glycosylation in collagen fibres [38]. Permanent degradation of the osteoarticular structures of the foot is commonly caused by chronic, often multiple joint inflammation. An additional factor is the instability of the body's balance, which increases the danger of falling. As a result, osteoporosis in diabetic patients is a secondary disease in coexisting kidney diseases, angiopathy, and so on. Research in patients with type I diabetes indicates an elevated number of fatigue fractures [39-44].

Furthermore, it should be noted that the relationship between diabetes mellitus and osteoporosis is imprecise, while bone density studies in the course of diabetes often do not present clear outcomes [45]. Nevertheless, considering the great importance of fracture prophylaxis in diabetic patients, which is strongly influenced by bone mineralisation, bone density, and elasticity, the authors believe that taking into account individual assessments of the coexistence of osteoporosis is a crucial priority. The studies show that over $50 \%$ of the general population with diabetes and $20 \%$ of younger people (aged 20-56) burdened with the disease fulfil the criteria of osteoporosis [46, 47]. The examination of patients at risk of Charcot's neuroosteoarthropathy is of particular importance, as, in these individuals, the bone mineral density has been significantly reduced [48]. It should be noted that within the feet there are relatively few cross-sectional studies on bone density, mineralisation, and so on.

On the internal level, the function of mechanical load detection is carried out by osteocytes [49-52]. Biomechanisms, aimed at the reconstruction of the bone structure and repair of microdamage, cause periodic boneweakening at the resorption site. During healing, this particular bone area (adhesion process) shows a periodically elevated fracture risk $[53,54]$.

On the external level, the key issue in the elimination of biomechanical abnormalities will be the diagnosis of body posture, including diagnostic methods aimed at the early detection of defective pressure distribution during standing, body balancing, and locomotion. As a consequence, these actions are aimed at defect correction, relief, and amortization. As a part of the prevention of fractures, pharmacological treatment, supplementation of vitamin D and calcium, and diet therapy are mainly recommended [55-57]. 
An important aspect is also the monitoring and treatment of comorbidities, that is, those that constitute the main cause of osteoporosis [58, 59]. Diagnostics of the musculoskeletal system is recommended mainly to patients at risk, mainly the elderly [60] and women in the postmenopausal age $[61,62]$. However, for younger people, routine tests are recommended [60]. Detailed imaging diagnostics is performed in the event of emerging clinical symptoms (pain, inflammation, and swelling). The most frequently recommended examination is X-ray, which, unfortunately, in the initial phase shows a low diagnostic sensitivity, increasing after about 3 months from the appearance of the first symptoms [63-68].

However, research and the scientific literature do not indicate detailed noninvasive diagnostic procedures. There are also no scientific and research reports in the area of foot assessment, including in particular the procedures for assessing the distribution of pressure within the feet.

From the authors' experience, the diagnosis of postural and functional defects of structures allows the early detection of the risk of fatigue fractures in patients with osteoporosis. Consequently, periodic tests allow the early implementation of effective measures to prevent fatigue fractures. Such activities are of particular importance in the prevention of foot fractures, mainly due to the significant gravitational overloads arising during locomotion. Considering the above, the authors made a detailed diagnosis of posture in 11 exemplary patients with osteoporosis, indicating at the same time diagnostic methods for the assessment of foot defects and deformities, and the analysis of pressure distribution during standing, walking, and body balancing.

The effects of the analysis of exemplary patients.

All figures and images have been prepared by the authors and are their property.

The analysis of patients included 11 exemplary patients with osteoporosis, aged 27-86, including eight men and 3 women with pain in the feet, ankle joint, and/or shin, with a limited range of mobility. Two patients additionally suffer from diabetes; four of them have a history of fatigue fractures. In all these patients, postural diagnostics was performed, with particular emphasis on the assessment of foot and lower limb defects using traditional posturological methods, including pedobarography in diagnostic procedures, which is used to assess the distribution of pressure in the standing and locomotion position and the balance test.

Table 1 presents the results of tests of 11 patients, indicated in this publication, and photogrammetric research, which were accompanied by anthropometry of the foot and podoscopic tests in individual sectors of the foot including the following:

Arch height measurements that have been combined with the plantar part assessment

Goniometric assessment of the walk angle and toes position
The results of the examinations of the feet performed in patients with osteoporosis indicate that 9 out of 11 suffer from tarsal valgus. Seven patients presented hallux valgus and defects of the toes from II to V. However, the comparison of the results of the X-ray with the outcomes of the tests indicates that each patient has a different problem and, as a consequence, a different cause of pain and distortion. The clinical exemplary patients presented in this publication show asymmetrical and chaotic dysfunctions of the foot and structural instability. Given the fact that patients have individually specific changes, the diagnostic procedure indicated by the authors points to the necessity of individual determination of the needs in terms of relief, shock absorption, and correction to be performed in patients with osteoporosis.

Below are photographic documentation of 9 patients, that is, X-ray, magnetic resonance imaging, and podoscopic research, which used selected elements of functional diagnostics and anthropometry.

During X-ray tests, hallux valgus with an overload of the metatarsophalangeal joint in the area of MTP I and frequent subluxation of sesamoid bones was observed in five patients. Among four patients, enthesopathy of the plantar fascia was detected. In the case of 4 exemplary patients, fractures within the foot bone were observed, in one exemplary patient case tibial, and fibula bone fractures occurred. The analysis of $\mathrm{X}$-rays shows numerous overload changes in the region of the foot, which is manifested by calcifications and osteophytes in the joints and defective trabeculation.

The assessment of the pressure on the arch of the foot when standing and walking will be crucial in the early detection of increased pressure. For this purpose, a pedobarographic test was carried out under both static and dynamic conditions (Figure 10(a). Evaluation of pressure during standing/Figure 10(b): assessment of pressure during walking).

The analysis included the values of pressure in individual metaplanes, determined according to the model, and markings indicate pressure on individual sectors of the foot:

$\mathrm{MH}$-internal part of the tarsus/LH-external part of the tarsus: allows the reading of pressure, with the correlation of results based on the outcomes of anthropometric tests of valgus/varus tarsus deformity/ tarsus instability, both while standing and walking

$\mathrm{MF}$-metatarsus: allows the pressure on the metatarsus to be assessed; this is especially important in assessing pressure during walking

M 1-5-pressure on the metatarsophalangeal joints: allows conclusions to be drawn on the functionality of the transverse arch

T1-pressure on the great toe and T2-5-pressure on the toes $2-5$

The results of the examination show a significant overload of the forefoot, with fractures and degradation of the 3rd metatarsal head (M3 meta surface). It is noteworthy 
TABLE 1: Summary of general information, defects, and ailments of the feet of patients included in the study, together with an assessment of functionality in individual areas of the foot (foot, longitudinal arch, transverse arch, and toes).

\begin{tabular}{|c|c|c|c|c|c|c|c|}
\hline \multirow{2}{*}{$\begin{array}{l}\text { Patient no./ } \\
\text { figure no. }\end{array}$} & \multicolumn{3}{|c|}{ Medical history } & \multicolumn{4}{|c|}{ Diagnosed foot defects while standing } \\
\hline & $\begin{array}{c}\text { Age } \\
\text { (years) }\end{array}$ & $\begin{array}{l}\text { Weight } \\
(\mathrm{kg})\end{array}$ & $\begin{array}{l}\text { Medical history, } \\
\text { complaints }\end{array}$ & Tarsus & Longitudinal arch & Transverse arch & Toes \\
\hline $\begin{array}{l}\text { No. } 1 \\
\text { Figures 1(a)- } \\
1(\mathrm{e})\end{array}$ & 69 & 70 & $\begin{array}{l}\text { Pain in the forefoot, } \\
\text { both right and left. } \\
\text { Limited mobility in } \\
\text { the upper ankle joint }\end{array}$ & $\begin{array}{l}\text { L-valgus } \\
\text { R-normal }\end{array}$ & $\begin{array}{l}\text { L-reduced R-normal } \\
\text { (planovalgus foot in the } \\
\text { gait assessment of both } \\
\text { feet-pedobarography) }\end{array}$ & L-reduced R-reduced & $\begin{array}{l}\text { L-normal R- } \\
\text { normal }\end{array}$ \\
\hline $\begin{array}{l}\text { No. } 2 \\
\text { Figures 2(a)- } \\
\text { 2(f) }\end{array}$ & 86 & & $\begin{array}{l}\text { Comminuted fracture } \\
\text { of the fibula, tibia }\end{array}$ & $\begin{array}{l}\text { L-post } \\
\text { fracture } \\
\text { valgity R- } \\
\text { valgity }\end{array}$ & L-reduced R-reduced & L-reduced R-reduced & $\begin{array}{l}\text { L-hallux valgus } \\
\text { R-hallux valgus }\end{array}$ \\
\hline No. 3 & 66 & 65 & $\begin{array}{l}\text { Ankle swelling, foot } \\
\text { pain }\end{array}$ & $\begin{array}{l}\text { L-valgity } \\
\text { R-valgity }\end{array}$ & $\begin{array}{l}\text { L-normal R-normal } \\
\text { (planovalgus foot in the } \\
\text { gait assessment of both } \\
\text { feet-pedobarography) }\end{array}$ & L-reduced R-reduced & $\begin{array}{l}\text { L-normal R- } \\
\text { normal }\end{array}$ \\
\hline $\begin{array}{l}\text { No. } 4 \\
\text { Figures 3(a)- } \\
\text { 3(f) }\end{array}$ & 55 & 85 & $\begin{array}{l}\text { Pain of the whole foot } \\
\text { hindering walking, } \\
\text { venous insufficiency }\end{array}$ & $\begin{array}{l}\text { L-varus } \\
\text { deformity } \\
\text { R-varus } \\
\text { deformity }\end{array}$ & $\begin{array}{c}\text { Varus forefoot-instability } \\
\text { at the level of the } \\
\text { tarsometatarsal joints }\end{array}$ & L-reduced R-reduced & $\begin{array}{c}\text { L-hallux } \\
\text { valgus, II-V- } \\
\text { hammer toes } \\
\text { R-hallux } \\
\text { valgus, II-V } \\
\text { varus toes } \\
\text { (fixed lesions- } \\
\text { X-ray) }\end{array}$ \\
\hline $\begin{array}{l}\text { No. } 5 \\
\text { Figures 4(a)- } \\
4(c)\end{array}$ & 58 & 95 & Foot pain & $\begin{array}{l}\text { L-valgity } \\
\text { R-valgity }\end{array}$ & $\begin{array}{l}\text { L-normal R-normal } \\
\text { (planovalgus foot in the } \\
\text { gait assessment of both } \\
\text { feet-pedobarography) }\end{array}$ & L-reduced R-reduced & $\begin{array}{c}\mathrm{L}-\text { hallux } \\
\text { valgus, flexible } \\
\text { hammer toes- } \\
\text { hallux valgus, } \\
\text { flexible } \\
\text { hammer toes }\end{array}$ \\
\hline $\begin{array}{l}\text { No. } 6 \\
\text { Figures 5(a)- } \\
5(e)\end{array}$ & 71 & 91 & $\begin{array}{c}\text { Pain in the area of the } \\
\text { first } \\
\text { metatarsophalangeal } \\
\text { joint, limitation of } \\
\text { mobility. Diabetes II, } \\
\text { renal failure, } \\
\text { psoriasis, prostate } \\
\text { hypertrophy, } \\
\text { hypertension, heart } \\
\text { failure, fatty liver, } \\
\text { lymphoedema }\end{array}$ & $\begin{array}{l}\text { L-valgity } \\
\text { R-valgity }\end{array}$ & $\begin{array}{l}\text { L-normal R-normal } \\
\text { (planovalgus foot in the } \\
\text { gait assessment of both } \\
\text { feet-pedobarography) }\end{array}$ & $\begin{array}{l}\text { L-reduced R-reduced } \\
\text { overload change } \\
\text { (callus) in the area of } \\
\text { II and III } \\
\text { metatarsophalangeal } \\
\text { joint }\end{array}$ & $\begin{array}{l}\text { L-hallux } \\
\text { valgus/rigid II, } \\
\text { IV varus toes/II } \\
\text { hammer toe P- } \\
\text { II-IV flexible } \\
\text { hammer toes }\end{array}$ \\
\hline $\begin{array}{l}\text { No. } 7 \\
\text { Figures 6(a)- } \\
6(\mathrm{~g})\end{array}$ & 27 & 87 & $\begin{array}{c}\text { Fracture of the } \\
\text { calcaneus with } \\
\text { fragmentation in } 2015\end{array}$ & $\begin{array}{l}\text { L-valgity } \\
\text { R-valgity }\end{array}$ & $\begin{array}{l}\text { L-normal P-normal } \\
\text { (planovalgus foot in the } \\
\text { gait assessment of both } \\
\text { feet-pedobarography) }\end{array}$ & L-reduced R-reduced & $\begin{array}{l}\text { L-normal R- } \\
\text { normal }\end{array}$ \\
\hline $\begin{array}{l}\text { No. } 8 . \\
\text { Figures } 7(a)- \\
7(e)\end{array}$ & 79 & 68 & $\begin{array}{l}\text { Pain of the left foot, of } \\
\text { the great toe, psoriasis }\end{array}$ & $\begin{array}{l}\text { L-valgity } \\
\text { R-valgity }\end{array}$ & $\begin{array}{l}\text { L-reduced R-reduced } \\
\text { (planovalgus foot in the } \\
\text { gait assessment of both } \\
\text { feet-pedobarography) }\end{array}$ & L-reduced R-reduced & $\begin{array}{c}\text { L-hallux } \\
\text { valgus, } \\
\text { dislocation of } \\
\text { the sesamoid } \\
\text { bones (X-ray) } \\
\text { R-hallux valgus }\end{array}$ \\
\hline
\end{tabular}


TABle 1: Continued.

\begin{tabular}{|c|c|c|c|c|c|c|c|}
\hline \multirow{2}{*}{$\begin{array}{l}\text { Patient no./ } \\
\text { figure no. }\end{array}$} & \multicolumn{3}{|c|}{ Medical history } & \multicolumn{4}{|c|}{ Diagnosed foot defects while standing } \\
\hline & $\begin{array}{c}\text { Age } \\
\text { (years) }\end{array}$ & $\begin{array}{l}\text { Weight } \\
(\mathrm{kg})\end{array}$ & $\begin{array}{l}\text { Medical history, } \\
\text { complaints }\end{array}$ & Tarsus & Longitudinal arch & Transverse arch & Toes \\
\hline No. 9. & 82 & 94 & $\begin{array}{l}\text { Significant valgity } \\
\text { and pain of the ankle } \\
\text { of the left limb; in the } \\
\text { right limb, the } \\
\text { condition is } \\
\text { complicated by } \\
\text { surgery due to hallux } \\
\text { valgus, } \\
\text { lymphoedema, no X- } \\
\text { ray-the patient does } \\
\text { not agree to the X-ray } \\
\text { image }\end{array}$ & $\begin{array}{l}\text { L-valgity } \\
\text { (the lack of } \\
\text { X-ray } \\
\text { image } \\
\text { prevents } \\
\text { making } \\
\text { diagnosis) } \\
\text { R-valgity }\end{array}$ & $\begin{array}{l}\text { L-reduced R- } \\
\text { reduced(pedobarography) }\end{array}$ & L-reduced R-reduced & $\begin{array}{c}\text { L-hallux } \\
\text { valgus, II-IV } \\
\text { hammer toesR- } \\
\text { significant } \\
\text { deformities of } \\
\text { the toes } \\
\text { (postoperative } \\
\text { complications) }\end{array}$ \\
\hline $\begin{array}{l}\text { No. } 10 . \\
\text { Figures } 8(a)- \\
8(e)\end{array}$ & 33 & 87 & $\begin{array}{l}\text { Pain of the II } \\
\text { metatarsophalangeal } \\
\text { joint of the left foot, } \\
\text { instability of the III } \\
\text { toe, microfractures } \\
\text { within the head of the } \\
\text { III metatarsal bone; } \\
\text { medical history } \\
\text { revealed numerous } \\
\text { microfractures in the } \\
\text { right hand, radius, } \\
\text { fibula-during } \\
\text { activities of daily } \\
\text { living (e.g. abnormal } \\
\text { body position) }\end{array}$ & $\begin{array}{l}\text { L-normal } \\
\text { R-normal }\end{array}$ & $\begin{array}{l}\text { L-normal R-normal } \\
\text { Adduction of the } \\
\text { metatarsal bones, } \\
\text { distortion at the level of } \\
\text { the line of lisfranc joints } \\
\text { (X-ray, pedobarography } \\
\text { indicates significant } \\
\text { pressure on the base of the } \\
\text { V metatarsal bone). When } \\
\text { standing, varus forefoot in } \\
\text { relation to the tarsus } \\
\text { (pedobarography) }\end{array}$ & $\begin{array}{c}\text { L-reduced R-reduced } \\
\text { in both feet, } \\
\text { significantly } \\
\text { increased pressure on } \\
\text { the II } \\
\text { metatarsophalangeal } \\
\text { joint } \\
\text { (pedobarography) } \\
\text { degradation of the } \\
\text { head of the II } \\
\text { metatarsal bone of the } \\
\text { left foot (X-ray) }\end{array}$ & $\begin{array}{l}\text { Toes (L and } \mathrm{R} \text { ) } \\
\text { apparent } \\
\text { features of the } \\
\text { Morton's foot } \\
\text { caused by } \\
\text { adduction of } \\
\text { the forefoot (X- } \\
\text { ray)II-V } \\
\text { flexible } \\
\text { hammer toes. } \\
\text { Significant } \\
\text { instability of } \\
\text { the II toe of the } \\
\text { left foot }\end{array}$ \\
\hline $\begin{array}{l}\text { No. } 11 \\
\text { Figures 9(a)- } \\
9(f)\end{array}$ & 66 & 82 & $\begin{array}{l}\text { L-amputation of the } \\
\text { toes I-IV, the } \\
\text { metatarsophalangeal } \\
\text { joints, as a result of } \\
\text { necrosis (circulatory } \\
\text { disorders), with an } \\
\text { episode of coma, pain } \\
\text { of the plantar surface }\end{array}$ & & & L-reduced R-reduced & $\begin{array}{l}\text { L-amputation } \\
\text { of toes I-IV, } \\
\text { varus fifth toe } \\
\text { (X-ray) P- } \\
\text { hallux valgus, } \\
\text { II-V flexible } \\
\text { hammer toes }\end{array}$ \\
\hline
\end{tabular}

L: left limb; R: right limb.

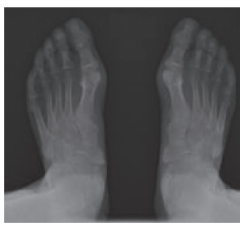

(a)

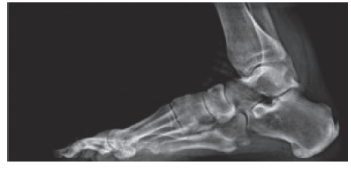

(b)

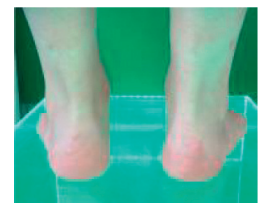

(c)

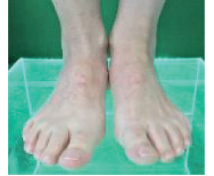

(d)

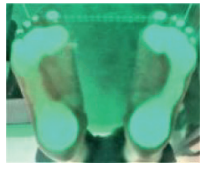

(e)

FIgURE 1: (a-e) Results of imaging tests (X-ray) and podoscopic tests: patient no. 1. (a). Dorsal-plantar foot X-ray: hallux valgus, subluxation of sesamoid bones, overloaded cuneometatarsal joint, and osteophytes in the area of navicular bone.(b) Lateral X-ray: Achilles tendon enthesopathy and numerous calcifications. (c) Posterior picture: ankle joint and hindfoot evaluation. (d) Anterior picture of the feet: assessment of toe positioning and deformation. (e) Plantar photo on the podoscope: evaluation of plantar part of the foot and height measurement of the longitudinal arch.

that the compensatory processes that reduce pain while standing do not activate while walking (despite persistent pain), while standing the foot is stabilized by the tarsometatarsal joints (TMTJ), which consequently makes the second and third metatarsal bones susceptible to fractures as a result of stress [69-71]. 


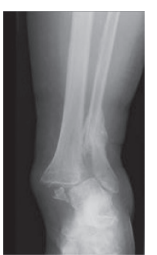

(a)

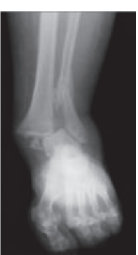

(b)

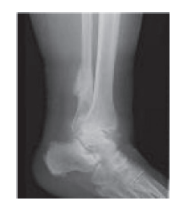

(c)

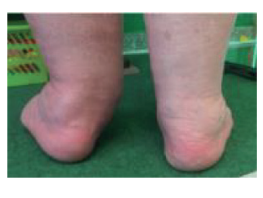

(d)

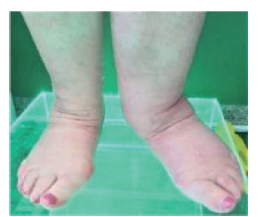

(e)

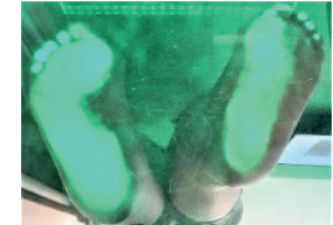

(f)

Figure 2: (a-f) Results of imaging tests (X-ray) and podoscopic tests: patient no. 2. (a) Posterior-anterior X-ray; fracture of the medial ankle and fracture of the distal end of the fibula. (b) Anterior-posterior X-ray: fracture of the medial ankle, fracture of the distal end of the fibula, overload changes in the phalangeal joints, and inflammation in the metatarsal joints. (c) Lateral X-ray: microfractures of the heel bone and enthesopathy of the plantar fascia: calcaneal spur. (d) Posterior picture: ankle joint and hindfoot evaluation. (e) Anterior picture of the feet: assessment of toe positioning and deformation. (f) Plantar photo on the podoscope: assessment of plantar part of the foot, height measurement of the longitudinal arch.

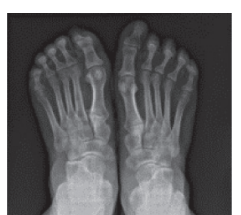

(a)

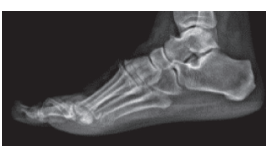

(b)

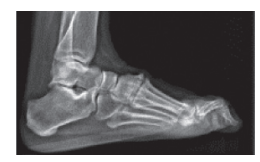

(c)

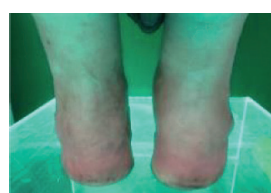

(d)

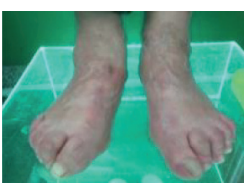

(e)

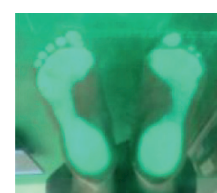

(f)

Figure 3: (a-f) Results of imaging tests (X-ray) and podoscopic tests: patient no. 4. (a) Dorsal-plantar foot X-ray: phalangeal valgity, degeneration of the interphalangeal joints, and additional navicular bone in the left foot. (b) Lateral X-ray: coronoid talus bone and degradation lesions in the phalangeal joints. (c) Lateral X-ray: coronoid talus bone and degradation lesions in the phalangeal joints. (d) Posterior picture: ankle joint and hindfoot evaluation. (e) Anterior picture of the feet: assessment of toe positioning and deformation. (f) Plantar photo on the podoscope: assessment of plantar part of the foot and height measurement of the longitudinal arch.

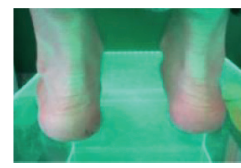

(a)

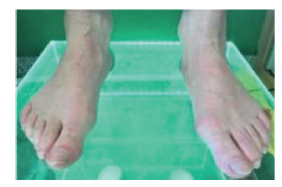

(b)

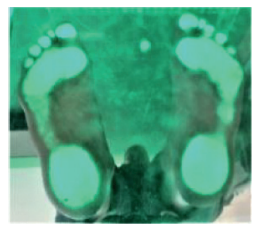

(c)

Figure 4: (a-c) Podoscopic tests: patient no. 5. (a) Posterior picture: ankle joint and hindfoot evaluation. (b) Anterior picture of the feet: assessment of toe positioning and deformation. (c) Plantar photo on the podoscope: assessment of plantar part of the foot and height measurement of the longitudinal arch.

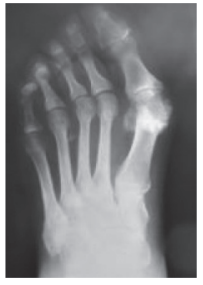

(a)

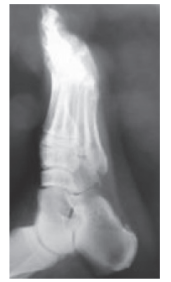

(b)

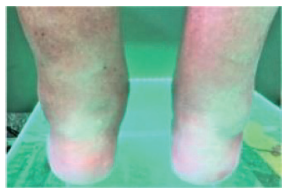

(c)

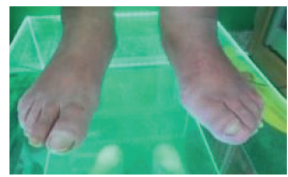

(d)

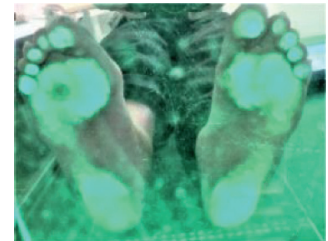

(e)

Figure 5: (a-f) Results of imaging tests (X-ray) and podoscopic tests: patient no. 6. (a) Dorsal-plantar foot X-ray: degeneration of the I head of metatarsal bones, phalangeal valgity, and overload lesions in metatarsophalangeal joints. (b) Lateral foot X-ray: enthesopathy of the plantar fascia and inflammation in the metatarsophalangeal joints. (c) Posterior photo: ankle joint and hindfoot evaluation. (d) Anterior picture of the feet: assessment of toe positioning and deformation. (e) Plantar photo on the podoscope: assessment of plantar part of the foot and height measurement of the longitudinal arch. 


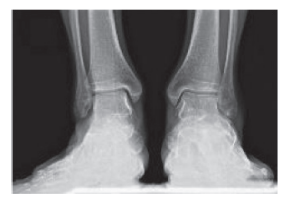

(a)

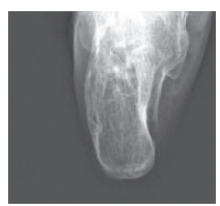

(b)

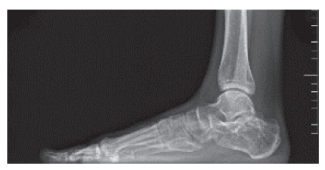

(c)

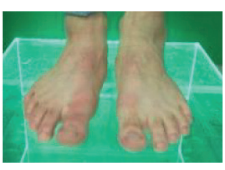

(f)

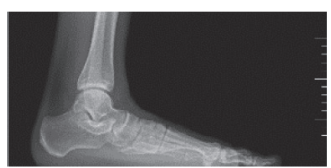

(d)

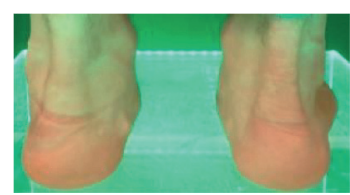

(e)

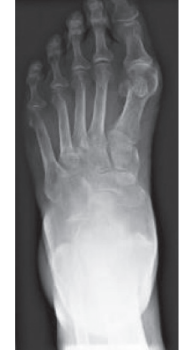

(a)

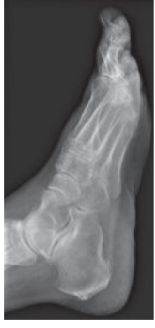

(b)

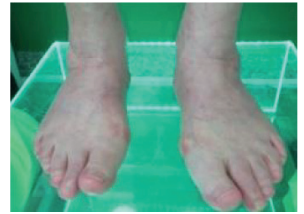

(d)

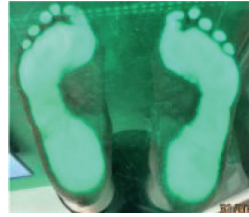

(e)

Figure 7: (a-e) Results of imaging tests (X-ray) and podoscopic tests: patient no. 8. (a) Dorsal-plantar X-ray: hallux valgus, subluxation of sesamoid bones, and overloaded cuneometatarsal joint. (b) Diagonal foot X-ray (lateromedial): enthesopathy of the plantar fascia and Achilles tendon, numerous calcifications, and overloads in the upper ankle joint. (c) Posterior picture: ankle joint and hindfoot evaluation. (d) Anterior picture of the feet: assessment of toe positioning and deformation. (e) Plantar photo on the podoscope: assessment of plantar part of the foot, height measurement of the longitudinal arch.

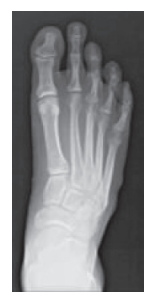

(a)

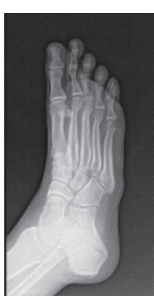

(b)

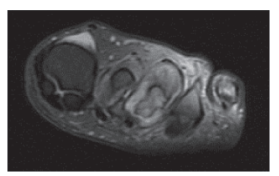

(c)

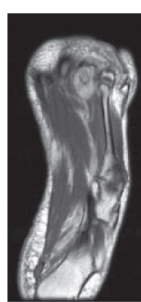

(d)
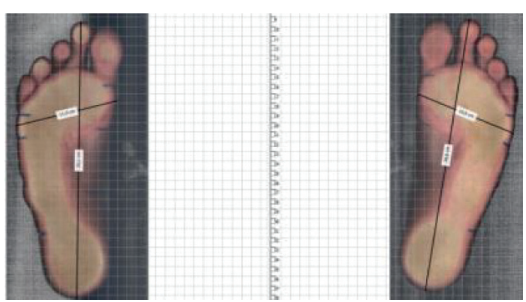

(e)

Figure 8: (a-e) Results of imaging tests (X-ray, MRI) and foot scanning: patient no. 10. (a) Dorsal-plantar X-ray: degradation lesion of the III head of the metatarsal bone and numerous transverse calcifications. (b) Diagonal X-ray of foot 45: degradation lesion of the III head of metatarsal bone and numerous calcifications. (c) Magnetic resonance imaging with contrast: degradation lesion of the III head of the metatarsal bones and medial plantar nerve neuralgia. (d) Magnetic resonance imaging with contrast: degradation lesion of the III head of the metatarsal bone and medial plantar nerve neuralgia. (e) Plantar photo from 2D Scanner: assessment of plantar part of the foot and measurement of foot length and width. 


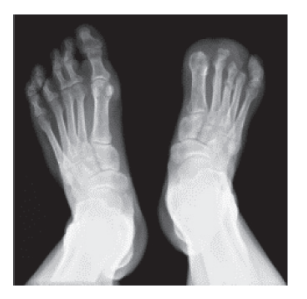

(a)

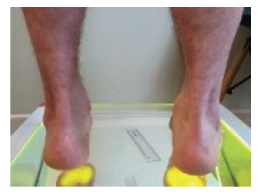

(d)

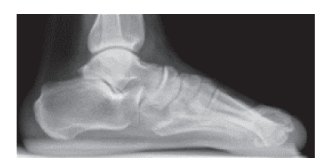

(b)

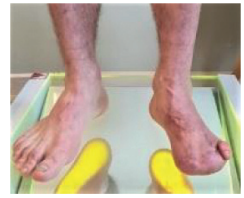

(e)

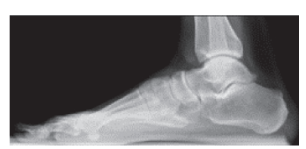

(c)

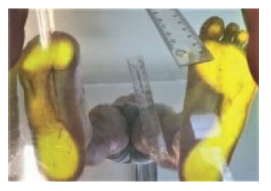

(f)

Figure 9: a-f) Results of imaging tests (X-ray) and podoscopic tests: patient no. 11. (a) Dorsal-plantar foot X-ray: fatigue fracture of the III metatarsal bone, amputation of toes I-IV in the left foot. (b) Lateral X-ray: amputation of toes I-IV, overload in the area of ankle joints, and talonavicular. (c) Lateral X-ray: overload in the area of ankle joints and talonavicular. (d) Posterior photo: ankle joint and hindfoot evaluation. (e) Anterior picture of the feet: assessment of toe positioning and deformation. (f) Plantar photo on the podoscope: assessment of plantar part of the foot and height measurement of the longitudinal arch.

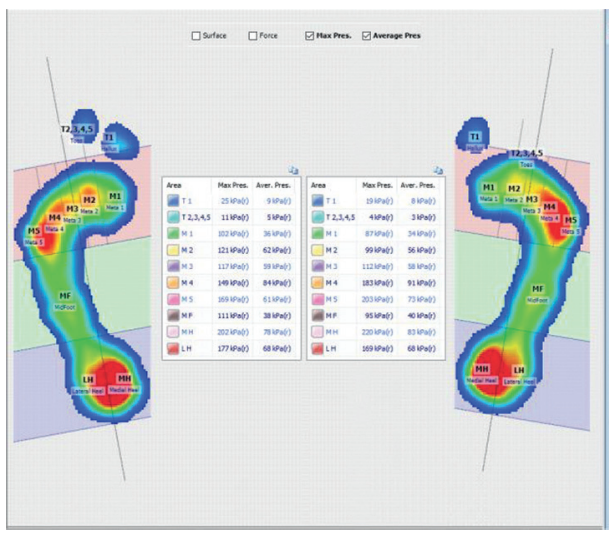

(a)

Figure 10: (a) The result of pedobarographic test when standing. metaplanes.

Patient no. 10 presented adduction and varus deformity of the forefoot at the level of the line of Lisfranc joints. This is also illustrated by the result $10 \mathrm{a}$, in the left foot:

Increased pressure on the heel in the $\mathrm{MH}$ area (which is confirmed by the diagnosis of valgity made in a physical examination).

Increasing pressure on the head of the 1st (M1) to the 5th (M2) metatarsal bone. This may be due to the fact that metatarsal bones, including the arch of the foot, are exposed to fatigue fractures.

The pedobarographic examination also allowed the assessment of spatial and temporal parameters during foot shunting. Figure 11 presents the results of the examination of the distribution of forces, pressure, and acceleration for patient no. 7 suffering from a fracture of the calcaneus.

The pressure distribution curve is repeatable, an increased pressure is observed on the forefoot of both feet, and

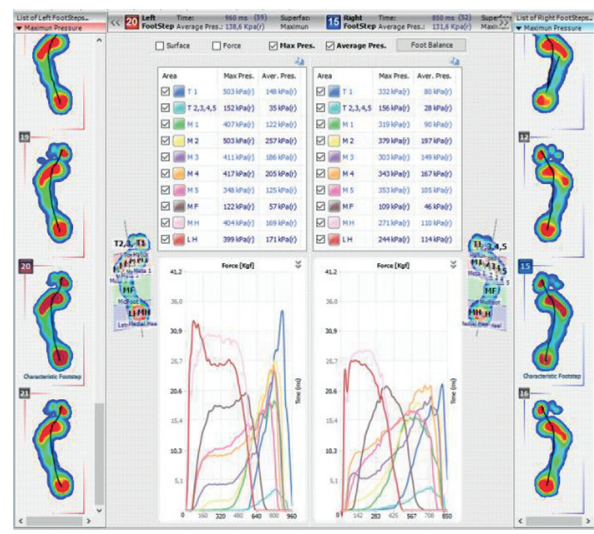

(b)

(b) While walking, patient no. 10, increased pressure on the M1-M5 this may be associated with a significant dispersion of the values of forces in individual footprints. This result may indicate instability of the structures of the upper and lower ankle.

The functionality of the longitudinal arch is assessed using pedobarography. A degree of arch arcing while standing is determined using the Biomech Studio software and the AI (Arch Index). The results presented in Figures 12(a) and 12(b) for patient no. 7 confirm instability of the foot structures, because selected traces while walking show asymmetrical and unique overpronation of the foot.

Comparative analysis of the results of foot arch examinations during standing and walking is used to assess the functionality of the feet. Six patients who are presented in this publication have overpronation of the foot, which allows a conclusion of planovalgus foot during walking to be drawn (i.e., lowering of the arch of the foot during the phase of push off and no lateral edge contact, i.e., no supination of the feet). 


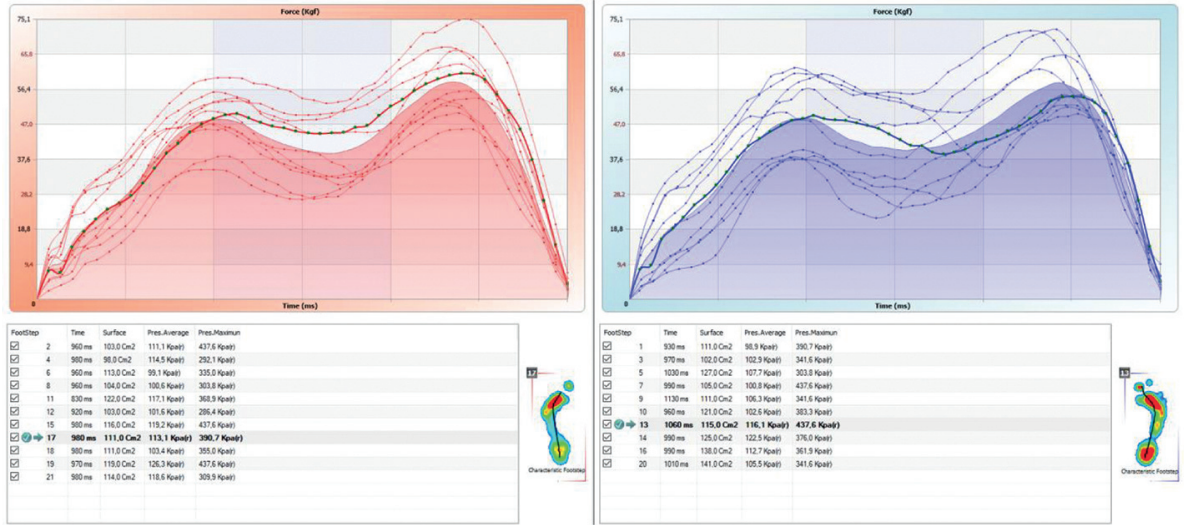

FIgURE 11: The results of the examination of the distribution of forces and time-space parameters while walking, patient no. 7.

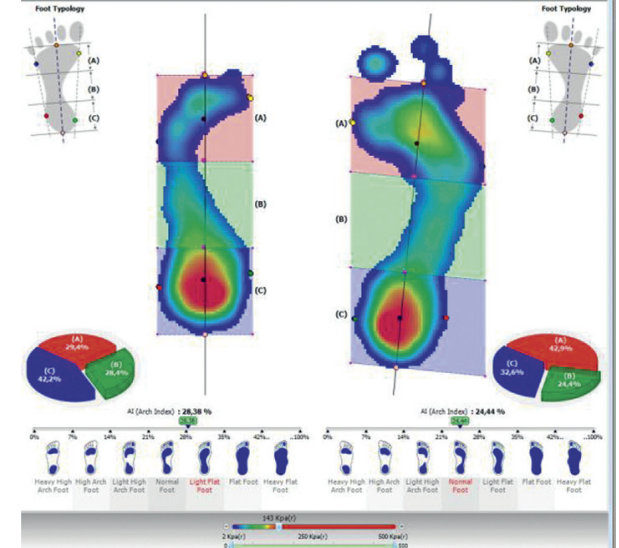

(a)

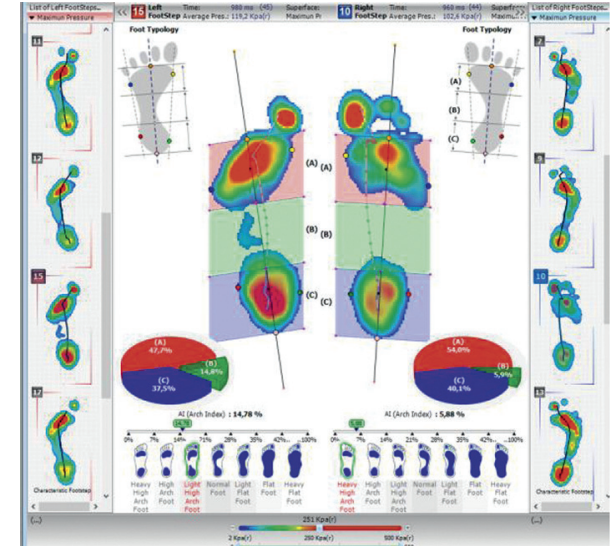

(b)

FiguRE 12: (a) The result of the foot arch examination when standing. (b) The result of foot arch examination while walking: patient no. 7.

The push off curve was also observed by pedobarography, as illustrated in Figure 13.

The ability to maintain balance, which is also assessed during a pedobarographic examination, is also important in assessing the distribution of pressure on the feet. Figure 14 shows the result of the balancing test in patient no. 7. The result indicates a significant imbalance, especially for the lateral oscillations of the COP (Figure 14).

The pedobarography has a very wide diagnostic spectrum, while both standing and walking. Therefore, it is widely used in the prevention of fractures resulting from overloads. These include, in particular, osteoporosis.

\section{Discussion}

In the prophylaxis of secondary fractures, which occur during the curing process, it is essential to create the appropriate conditions through two factors:

(I) Elimination of improper pressure, through depreciation and relief

(II) Targeting of its accurate distribution

These factors are strategic goals in the process of reducing clinically visible changes $[37,72]$. In the course of the diagnostics and therapy, the time periods of the applied procedures should be taken into account. This emphasises the fact that after the reconstruction phase in patients with osteoporosis, the bone structure has an extended mineralisation time $[12,73]$.

Reduced bone density and weakened mechanisms of its reconstruction, repair of microdamage, defects in the microarchitecture of the trabeculae, and the porosity and thinning of the cortical layer require rapid prophylactic actions, starting at the level of loads arising in the course of everyday life [74-77]. However, this does not indicate the exclusion from activity, as it has been proven that immobilisation does not promote bone remodelling [78-80]. The skeletal system has an autoprogramme, targeted at the thinning of unused bone, which was observed in military workers as well as professional athletes. Thus, raising the load on the bone raises its weight. Nevertheless, it should be emphasised that improper pressure distribution may promote the local accumulation of microdamage. In the case of an incorrect tension level, the process of decreasing/increasing of bone mass may result in microdamage and, in the long term, may cause morphological changes of bones, which through a loss of elasticity may often result in noticeable fractures [51, 81-83]. This phenomenon particularly 

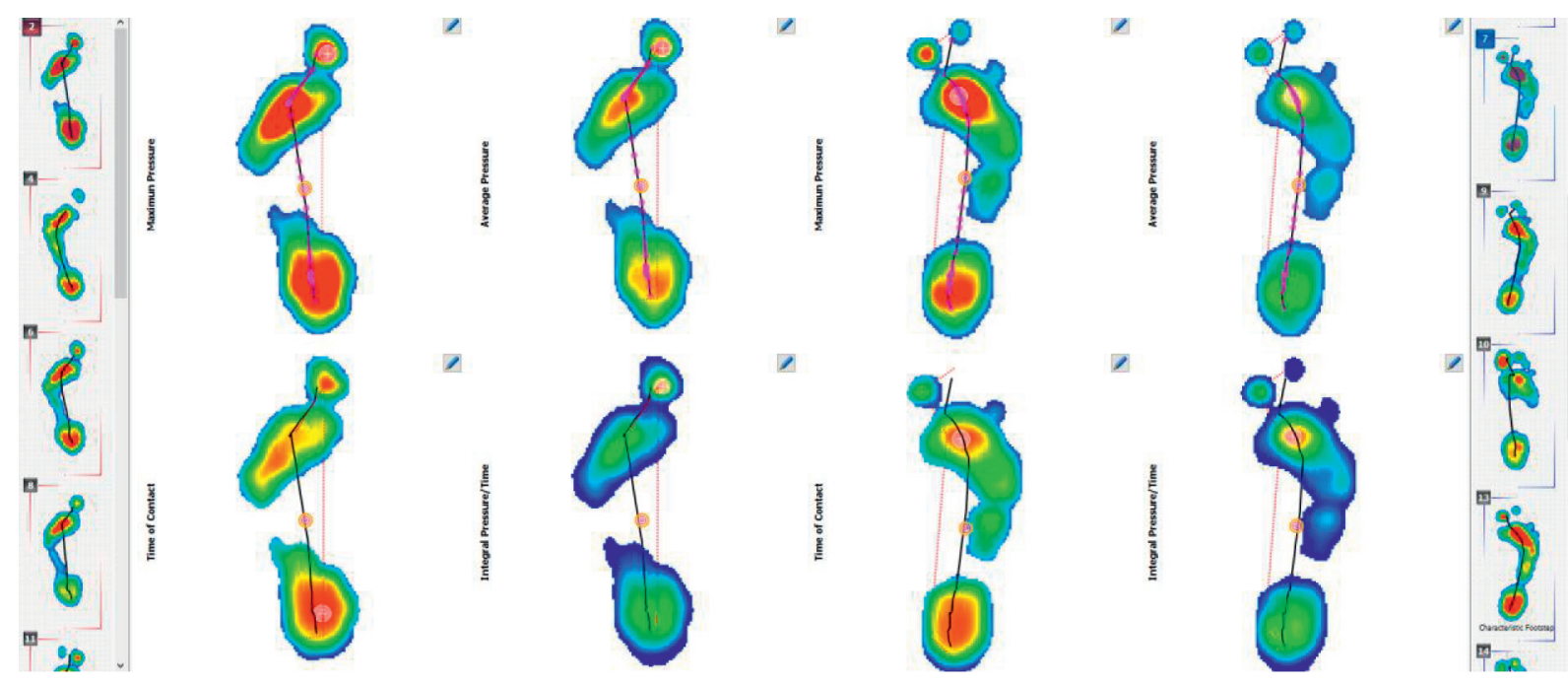

FIgURE 13: The assessment of the progression of the condition for patient no. 7: push off curve; the thin red line depicts overpronation propulsion of the left foot.

concerns the foot, because its function, apart from locomotion, is postural stabilisation when standing and walking. The feet accommodate to the surface changes and movements performed by a person, changing the length of soft structures and the arrangement of hard ones and then subsequently returning to their architecture at the moment of relief. Another function of the foot is to act as a shock absorber, which not only exposes it to numerous overload changes but also to microinjuries resulting from excessive impacts and stress pressure [84-86].

In the assessment of the foot's condition, and especially in the activities focused on the prevention of overload changes, the diagnosis of its dynamic parameters and support function has a significant role. Adjusting the pressure distribution, carried out in the process of microdamage prophylaxis, should, therefore, be a process of balancing between the motor activity and simultaneous elimination of excessive load, arising during everyday life activities [87-91]. In a physical activity schedule, an essential role of rest, as well as periodic breaks in training, was indicated, as part of fatigue fracture prevention [92]. Antigravitational exercises, such as swimming, will play a significant function in the time of demand for periodical relief and in individuals at risk of fracture formation $[93,94]$. The return to regular activity should be strictly supervised and based on an accurate diagnostic-rehabilitation plan $[69,95]$.

The recommended treatment, as a component of fracture prophylaxis, mainly involves the initiation of pharmacological treatment, after prior bone density diagnosis and/or $\mathrm{X}$-ray examination. Diet therapy, healthy lifestyle, and vitamin D and calcium supplementation reduces the fracture risk; nevertheless, it is suggested to estimate the intake of calcium due to controversies related to its supply and risk of cardiovascular diseases [55-57]. In the therapy of osteoporosis, bisphosphonates are the fundamental pharmacological agents. The remaining drugs are aimed at reducing the risk of nonvertebral and hip fractures, as well as treating systemic diseases that are the main cause of osteoporosis $[58,59]$. International guidelines and recommendations for the pharmacological treatment of osteoporosis indicate minor differences, particularly in the age range of patients $[11,61,96-98]$. There are few reports in the research and scientific literature that would indicate an important role in the prevention of fractures and therapy through the use of individual orthopaedic insoles, specialist footwear, orthopaedic cushioning, and relieving elements. In the opinion and recommendations of the authors, it should be extended and include a significant role of relieving, amortization and correcting defects and dysfunctions of the foot, manifested during walking, running, standing, and other life activities.

The research and scientific literature indicates that, in the area of locomotor system diagnostics, as well as in the investigation of fractures in the course of osteoporosis, a highly specialised imaging diagnostic examination remains the golden means (most often, these are X-ray examinations). This is performed in the majority of cases when the patient already reports specific clinical symptoms, such as pain during normal life functions [69]. This situation is frequently the case when a fracture has already occurred. However, there is no fatigue fracture classification system that can be applied to all bones. The estimation schemes, commonly quoted by Fredericson et al. [64], Aredt at al. [65], and Nattiv et al. [66], do not include any recommendations for foot assessment. Although X-ray examinations are easy to perform and relatively inexpensive, they show a low sensitivity $(15 \%-35 \%)$ in the initial phase of lesions, which increases about 3 months after the first symptoms appeared $[67,68]$.

The scientific and research literature does not indicate specific diagnostic procedures. The studies of patients with osteoporosis, reviewed in this publication, showed a chaotic and asymmetrical and highly individualized course of dysfunctions in the area of defects and diseases of the lower extremities. According to the authors, individual differences are closely related to coexisting diseases, in particular to postural defects, with a very individualized course. This is an 


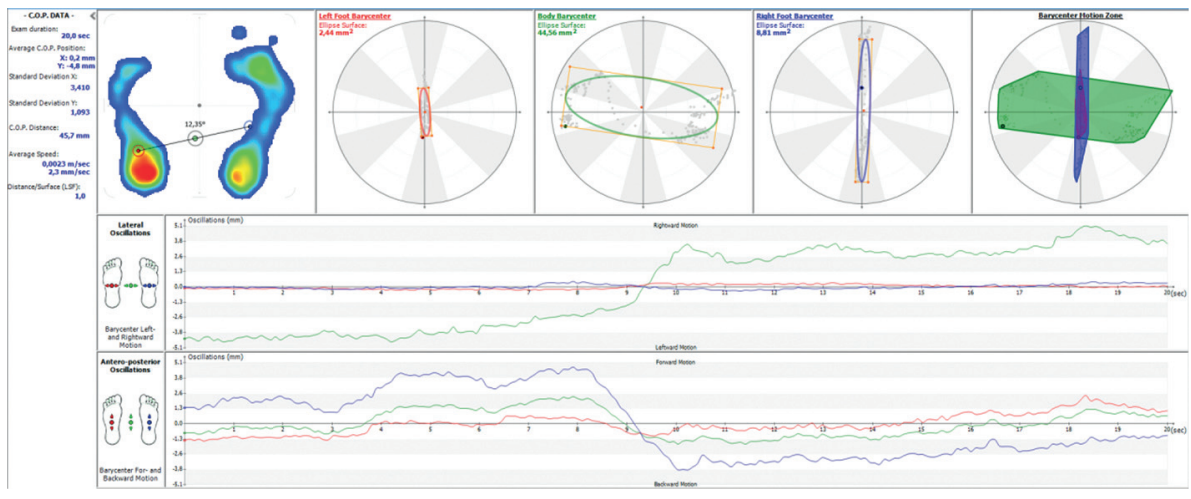

FIgURE 14: The result of the balance test for patient no. 7 .

important postulate for further research aimed at the creation of diagnostic procedures, which are procedures applicable in the prevention of fractures in the course of osteoporosis. The imaging diagnostics recommended so far, due to its intended use, obviously do not constitute preventive procedures for the early detection of fatigue fracture threats. According to the authors, early detection of defects, distortions, gait disturbances, and mobility of structures (including in particular structural instability) will be an important aspect of preventing osteoporotic (and other fractures arising in the course of low bone density) fractures.

In the course of prophylaxis, screening is recommended, including women aged over 65 and men aged over 75 , among patients at risk. Recommendations are population studies of older people; younger ones should be routinely assessed [60] and all women after menopause [61, 62]. Within the field of foot diagnostics, the interdisciplinary role of the medical team is crucial [99]. According to the authors, considering only the elderly in the screening diagnosis, and thus examining younger people only in the case of emerging clinical symptoms, significantly reduces the effectiveness of preventive measures.

Preventive actions in the area of fractures in the course of osteoporosis should be focused on precise feet screening diagnostics and, also, due to the fact of a close relationship between the action of forces during everyday life activities and the formation of microfractures, breakages, and a lack of adhesions, in patients with reduced bone density (BMD) $[100,101]$. It is estimated also that the occurrence of osteoporotic fractures in the foot is rising, mainly due to the fact of the ageing of the population and the increase within the number of people exercising above 50 years [63]. Another important element determining microdamage and bone fractures is the body mass index (BMI), which applies to each age group, that is, both elderly and adolescents [102-104].

According to the researchers, the diagnosis of pressure distribution through pedobarography is crucial for the prevention of tissue destruction within the foot. The assessment of defects and functions of the feet, especially during locomotion, serves for the precise detection of the causes of faulty distribution of the tensions. The essence is to differentiate the pressure that occurs while standing and walking, mainly due to the compensatory processes that maintain balance [105-107]. Pedobarography also allows for the assessment of the average time-space parameters and pressure forces especially during walking. This is a very important diagnostic aspect; it was assumed that considering that the heel stroke accounts for $110 \%$ of body weight and increases to $250 \%$ of body weight during running, the pressure distribution on the forefoot increases by about $40 \%-50 \%[108,109]$. The prevention of fatigue fractures should include monitoring pressure forces over time and measuring the values of acceleration of the foot during the phase of push off. Disturbances in the distribution and directions of forces are an absolute determinant of overload fractures. Drawing conclusions on pressure distribution disorders is of key importance, in particular in the assessment of the average obtained for a large number of samples, acquired in one patient. As a result of the pedobarographic examination, the result is obtained regarding the foot arch, pronation and supination functions, so it is also possible to infer about the foot structure and function during walking. All these aspects constitute important conclusions regarding the stability of structures, locally and globally (i.e., the balance of the body when standing). Instability of the foot structures not only can cause imbalance during walking, which promotes injury during a fall, but also can be manifested as imbalance when standing. The prevention of fractures should include the prevention of falls, in particular in patients with bone density deficits $[11,61]$. In addition, patients at increased risk of falling should be given high doses of vitamin D [57]. The development of osteoporosis is promoted by an overload of the musculoskeletal system, body weight transfer during locomotion (movement), and losing and regaining balance. The lower limbs are particularly overloaded in the exemplary patient [110].

The balance test is an important aspect of functional diagnostics of the musculoskeletal system; combined in one device (i.e., a pedobarograph), it significantly reduces the cost of biomechanical diagnostics [111-118]. Also, when bone structures are injured, both crushing and microfractures are noticed; current observations through noninvasive diagnostic methods and the implementation of relieving measures are of great importance in the prevention of complications, including the avoidance of secondary fractures. 
It seems evident that deformities in the feet and lower limbs, and generally defects in posture, will encourage the formation of defective pressure distribution and a point increase in its value. At the same time, whereas the structural instability induced by osteoporosis will favour the occurrence of defects, structural inefficiencies, and balance disorders, we may speak of a kind of "vicious circle" of events. Therefore, according to the authors, the screening of patients with osteoporosis will also be crucial within the following:

Initial assessment of foot defects, for example, valgus/ varus deformity of the tarsus, height of the vault, and deformations of the toes (mallet toes, claw toes, hallux valgus, and varus toes)

Reliable estimation of pressure distribution under static conditions

Evaluation of foot progression during walking, running, and other types of locomotion

Disturbances of the gait determination in terms of defective pressure distribution, including particularly the relationship of increased tension during prolonged contact of the foot with the ground

The importance of patient education in the field of foot observation and fast intervention in case of local pain, redness, and local body temperature increase [119-121]

Screening tests of feet should consist of the assessment of skin condition for hyperkeratosis, since the first symptoms of increased pressure within the feet are calluses and blisters, formed in the soles of the feet $[122,123]$. The analysis of pressure distribution is not only important in prevention and screening, but also an important aspect in planning relief procedures and individual orthopaedic supply [124]. Measurable and precise diagnostic methods of pressure (in point and global terms) and the assessment of time and contact surface of the plantar part of the feet with the ground should be used to design individual orthopaedic insoles and footwear $[125,126]$. It has been proven that orthopaedic insoles with individually designed elements of the foot arch (i.e., longitudinal and transverse arch) significantly improved body balance in older women with osteoporosis and were an important aspect of preventing falls, sprains, and so on [127].

The lack of ability to relieve the feet and no autocorrection during gait (supination/pronation) is one of the most important problems of patients with diabetes and its complications, for example, Charcot neuroosteoarthropathy [128]. This is an important aspect due to the fact that osteoporosis quite often statistically coexists with diabetes. It is necessary to implement targeted rehabilitation measures and appropriate relief, corrective and shock-absorbing supply in particular in the prevention of microfractures, ligament damage, and muscle atrophy in the course of sensory neuropathy [129]. The supply should take into account, first of all, important parameters showing foot dysfunction, gait disturbances, defects, and deformations [130-132]. Patient education and support in the selection of footwear with an individual orthopaedic insole are also necessary in the ho- listic prevention of fractures in osteoporosis. For the exemplary patient, footwear should be tailored to the needs of patients. This is particularly important in the prevention of fractures in patients with severe foot deformities in osteoporosis. These are also important postulates for further research and scientific works planned by the authors.

\section{Conclusions}

(1) The analysis of the literature showed that, apart from the diagnosis of bone density and the assessment of vitamin D levels, calcium levels, and so on, highly specialised imaging tests (mainly X-ray), used in the event of clinical symptoms, are the recommended diagnostic procedures in the area of the musculoskeletal system.

(2) Patients with osteoporosis show numerous individual deformities (defects), dysfunctions, and structural changes in the feet, which results in various disorders of pressure distribution. Extending diagnostics by periodic and screening tests, focused on assessing foot defects, balance disorders, and monitoring time-space parameters during gait will be an important aspect in the prevention of fractures in the course of osteoporosis.

(3) Pedobarography has a wide range of uses in periodic screening and ongoing foot diagnostics when the first symptoms of overload (e.g., corns, calluses, pain, and redness) have appeared.

(4) Instability and locally increased pressure are observed especially during locomotion; therefore, it is an important aspect to conduct a detailed analysis of patients while walking.

(5) In addition to supplementation and pharmacotherapy, the prevention of osteoporotic fractures should include the use of orthopaedic insoles, taking into account the patient-tailored design of elements to relieve and absorb shocks and correct deformations and defects.

\section{Conflicts of Interest}

The authors declare that there are no conflicts of interest regarding the publication of this article.

\section{References}

[1] L. A. G. Armas and R. R. Recker, "Pathophysiology of osteoporosis," Endocrinology and Metabolism Clinics of North America, vol. 41, no. 3, pp. 475-486, 2012.

[2] A. Blann, "An update on vitamin D deficiency and at risk groups," Journal of Family Health, vol. 25, no. 3, pp. 16-19, 2015.

[3] T. Welz, K. Childs, F. Ibrahim et al., "Efavirenz is associated with severe vitamin $\mathrm{D}$ deficiency and increased alkaline phosphatase," AIDS, vol. 24, no. 12, pp. 1923-1928, 2010.

[4] A. L. Skversky, J. Kumar, M. K. Abramowitz, F. J. Kaskel, and M. L. Melamed, "Association of glucocorticoid use and low 
25-hydroxyvitamin D levels: results from the National Health and nutrition examination survey (NHANES): 20012006," The Journal of Clinical Endocrinology \& Metabolism, vol. 96, no. 12, pp. 3838-3845, 2011.

[5] M. Cozzolino, M. Vidal, M. V. Arcidiacono, P. Tebas, K. E. Yarasheski, and A. S. Dusso, "HIV-protease inhibitors impair vitamin D bioactivation to 1,25-dihydroxyvitamin D," AIDS, vol. 17, no. 4, pp. 513-520, 2003.

[6] K. D. Cashman, K. G. Dowling, Z. Škrabáková et al., "Vitamin D deficiency in Europe: pandemic?" The American Journal of Clinical Nutrition, vol. 103, no. 4, pp. 1033-1044, 2016.

[7] World Health Organization Study Group, "Assessment of fracture risk and its application to screening for postmenopausal osteoporosis," World Health Organization Technical Report Series, vol. 843, pp. 1-129, 1994.

[8] C. Muschitz, J. Patsch, E. Buchinger et al., "Prevalence of vertebral fracture in elderly men and women with osteopenia," Wiener Klinische Wochenschrift, vol. 121, no. 15-16, pp. 528-536, 2009.

[9] E. S. Siris, Y.-T. Chen, T. A. Abbott et al., "Bone mineral density thresholds for pharmacological intervention to prevent fractures," Archives of Internal Medicine, vol. 164, no. 10, pp. 1108-1112, 2004.

[10] E. S. Siris, S. K. Brenneman, E. Barrett-Connor et al., "The effect of age and bone mineral density on the absolute, excess, and relative risk of fracture in postmenopausal women aged 50-99: results from the National Osteoporosis Risk Assessment (NORA)," Osteoporosis International, vol. 17, no. 4, pp. 565-574, 2006.

[11] National Osteoporosis Foundation, 2013 Clinician's Guide to Prevention and Treatment of Osteoporosis, NOF, Washington, DC, USA, 2013.

[12] G. Boivin, Y. Bala, A. Doublier et al., "The role of mineralization and organic matrix in the microhardness of bone tissue from controls and osteoporotic patients," Bone, vol. 43, no. 3, pp. 532-538, 2008.

[13] Y. Bala, S. Bare, G. Boivin et al., "Secondary mineralization and the microhardness of bone measured across menopause in women," The Journal of Bone and Mineral Research, vol. 24, no. 1, 2009.

[14] M. Tiefenbach, M. Scheel, A. Maier et al., "Osteomalazie-klinik, diagnostik und therapie," Zeitschrift für Rheumatologie, vol. 77, no. 8, pp. 703-718, 2018.

[15] M. B. Schaffler, K. Choi, and C. Milgrom, "Aging and matrix microdamage accumulation in human compact bone," Bone, vol. 17, no. 6, pp. 521-525, 1995.

[16] NIH Consensus Development Panel on Osteoporosis Prevention, "Diagnosis, and Therapy. Osteoporosis prevention, diagnosis, and therapy," JAMA, vol. 285, no. 6, pp. 785-789, 2001.

[17] C. M. Girgis, R. J. Clifton-Bligh, M. W. Hamrick, M. F. Holick, and J. E. Gunton, "The roles of vitamin D in skeletal muscle: form, function, and metabolism," Endocrine Reviews, vol. 34, no. 1, pp. 33-83, 2013 Feb.

[18] M. A. Reuss-Borst, U. Lange, M. Knochenkrankheit, and Osteomalazie, Aktuelle Rheumatologie, vol. 42, p. 228, 2017.

[19] H. C. Taylor, M. D. Fallon, and M. E. Velasco, "Oncogenic osteomalacia and inappropriate antidiuretic hormone secretion due to oat-cell carcinoma," Annals of Internal Medicine, vol. 101, no. 6, pp. 786-788, 1984.

[20] G. Liamis, H. J. Milionis, and M. Elisaf, "Medication-induced hypophosphatemia: a review," QJM, vol. 103, no. 7, pp. 449-459, 2010.
[21] K. Konishi, M. Nakamura, H. Yamakawa et al., "Hypophosphatemic osteomalacia in von Recklinghausen neurofibromatosis," The American Journal of the Medical Sciences, vol. 301, no. 5, pp. 322-328, 1991.

[22] D. M. Reese and P. J. Rosen, "Oncogenic osteomalacia associated with prostate cancer," Journal of Urology, vol. 158, no. 3, p. 887, 1997.

[23] A. Al Kaissi, C. Windpassinger, F. B. Chehida et al., "How frequent is osteogenesis imperfecta in patients with idiopathic osteoporosis?" Case Reports, Medicine (Baltimore), vol. 96, no. 35, p. e7863, 2017.

[24] S. M. McKinlay, N. L. Bifano, and J. B. McKinlay, "Smoking and age at menopause in women," Annals of Internal Medicine, vol. 103, no. 3, pp. 350-356, 1985.

[25] S. Kousteni, T. Bellido, L. I. Plotkin et al., "Nongenotropic, sex-nonspecific signaling through the estrogen or androgen receptors," Cell, vol. 104, no. 5, pp. 719-730, 2001.

[26] R. Recker, J. Lappe, K. Davies, and R. Heaney, "Characterization of perimenopausal bone loss: a prospective study," Journal of Bone and Mineral Research, vol. 15, no. 10, pp. 1965-1973, 2000.

[27] R. P. Heaney, R. R. Recker, and P. D. Omaha, "Menopausal changes in calcium balance performance," Nutrition Reviews, vol. 41, no. 3, pp. 86-89, 1983.

[28] M. N. Weitzmann and R. Pacifici, "The role of T lymphocytes in bone metabolism," Immunological Reviews, vol. 208, no. 1, pp. 154-168, 2005.

[29] D. E. Hughes, A. Dai, J. C. Tiffee, H. H. Li, G. R. Mundy, and B. F. Boyce, "Estrogen promotes apoptosis of murine osteoclasts mediated by TGF- $\beta$," Nature Medicine, vol. 2, no. 10, pp. 1132-1136, 1996.

[30] G. Yan, Y. Huang, H. Cao, J. Wu, N. Jiang, and X. Cao, "Association of breastfeeding and postmenopausal osteoporosis in Chinese women: a community-based retrospective study," BMC Womens Health, vol. 19, no. 1, p. 110, 2019.

[31] R. L. Duckham, N. Peirce, C. Meyer, G. D. Summers, N. Cameron, and K. Brooke Wavell, "Risk factors for stress fracture in female endurance athletes: a cross-sectional study," BMJ Open, vol. 2, no. 6, 2012.

[32] M. E. Brunet, S. D. Cook, M. R. Brinker, and J. A. Dickinson, "A survey of running injuries in 1505 competitive and recreational runners," The Journal of Sports Medicine and Physical Fitness, vol. 30, no. 3, pp. 307-315, 1990.

[33] R. A. Shaffer, M. J. Rauh, S. K. Brodine, D. W. Trone, and C. A. Macera, "Predictors of stress fracture susceptibility in young female recruits," The American Journal of Sports Medicine, vol. 34, no. 1, pp. 108-115, 2006.

[34] G. Yan, Y. Huang, H. Cao, J. Wu, N. Jiang, and X. Cao, "Association of breastfeeding and postmenopausal osteoporosis in Chinese women: a community-based retrospective study," BMC Womens Health, vol. 19, p. 110, 2019.

[35] M. Michalopoulou, A. Kambas, D. Leontsini et al., "Physical activity is associated with bone geometry of premenarcheal girls in a dose-dependent manner," Metabolism, vol. 62, no. 12, pp. 1811-1818, 2013.

[36] S. J. Iqbal, I. Kaddam, W. Wassif, F. Nichol, and J. Walls, "Continuing clinically severe vitamin D deficiency in Asians in the UK (Leicester)," Postgraduate Medical Journal, vol. 70, no. 828, pp. 708-714, 1994.

[37] D. B. Burr, C. H. Turner, P. Naick et al., "Does microdamage accumulation affect the mechanical properties of bone?" Journal of Biomechanics, vol. 31, no. 4, pp. 337-345, 1998.

[38] E. J. Daley, P. D. Pajevic, S. Roy, and P. C. Trackman, "Impaired gastric hormone regulation of osteoblasts and 
lysyl oxidase drives bone disease in diabetes mellitus," JBMR Plus, vol. 3, no. 10, Article ID e10212, 2019.

[39] L. McCabe, J. Zhang, and S. Raehtz, "Understanding the skeletal pathology of type 1 and 2 diabetes mellitus," Critical Reviews in Eukaryotic Gene Expression, vol. 21, no. 2, pp. 187-206, 2011.

[40] U. Stumpf, P. Hadji, L. van den Boom, W. Böcker, and $\mathrm{K}$. Kostev, "Incidence of fractures in patients with type 1 diabetes mellitus-a retrospective study with 4420 patients," Osteoporosis International, vol. 31, pp. 1315-1322, 2020.

[41] G. Karsenty, "Convergence between bone and energy homeostases: leptin regulation of bone mass," Cell Metabolism, vol. 4, no. 5, pp. 341-348, 2006.

[42] S. Ergun and Y. Yildirim, "The cole midfoot osteotomy: clinical and radiographic retrospective review of five patients (six feet) with different etiologies," Journal of the American Podiatric Medical Association, vol. 109, no. 3, pp. 180-186, 2019.

[43] J. J. Cao, "Effects of obesity on bone metabolism," Journal of Orthopaedic Surgery and Research, vol. 6, no. 1, p. 30, 2011.

[44] S. Dabash, E. D. Eisenstein, E. Potter, N. Kusnezov, A. M. Thabet, and A. A. Abdelgawad, "Unstable Ankle fracture fixation using locked fibular intramedullary nail in high-risk patients," The Journal of Foot and Ankle Surgery, vol. 58 , no. 2, pp. 357-362.

[45] G. Leidig-Bruckner and R. Ziegler, "Diabetes mellitus a risk for osteoporosis?" Experimental and Clinical Endocrinology \& Diabetes, vol. 109, no. 2, pp. S493-S514, 2001.

[46] S. A. G. Kemink, A. R. M. M. Hermus, L. M. J. W. Swinkels, J. A. Lutterman, and A. G. H. Smals, "Osteopenia in insulindependent diabetes mellitus; prevalence and aspects of pathophysiology," Journal of Endocrinological Investigation, vol. 23, no. 5, pp. 295-303, 2000.

[47] L. R. McCabe, "Understanding the pathology and mechanisms of type I diabetic bone loss," Journal of Cellular Biochemistry, vol. 102, no. 6, pp. 1343-1357, 2007.

[48] H. A. El Oraby, M. M. Abdelsalam, Y. M. Eid, R. El Hilaly, and H. A. Marzouk, "Bone mineral density in type 2 diabetes patients with Charcot arthropathy," Current Diabetes Reviews, vol. 15, no. 5, pp. 395-401, 2019.

[49] L. F. Bonewald and M. L. Johnson, "Osteocytes, mechanosensing and Wnt signaling," Bone, vol. 42, no. 4, pp. 606-615, 2008.

[50] L. Cardoso, B. C. Herman, O. Verborgt, D. Laudier, R. J. Majeska, and M. B. Schaffler, "Osteocyte apoptosis controls activation of intracortical resorption in response to bone fatigue," Journal of Bone and Mineral Research, vol. 24, no. 4, pp. 597-605, 2009.

[51] B. C. Herman, L. Cardoso, R. J. Majeska, K. J. Jepsen, and M. B. Schaffler, "Activation of bone remodeling after fatigue: differential response to linear microcracks and diffuse damage," Bone, vol. 47, no. 4, pp. 766-772, 2010.

[52] L. F. Bonewald, "The amazing osteocyte," Journal of Bone and Mineral Research, vol. 26, no. 2, pp. 229-238, 2011.

[53] A. M. Parfitt, C. H. Mathews, A. R. Villanueva, M. Kleerekoper, B. Frame, and D. S. Rao, "Relationships between surface, volume, and thickness of iliac trabecular bone in aging and in osteoporosis. Implications for the microanatomic and cellular mechanisms of bone loss," Journal of Clinical Investigation, vol. 72, no. 4, pp. 1396-1409, 1983.

[54] P. Garnero, E. Sornay-Rendu, M. C. Chapuy, and P. D Delmas, "Increased bone turnover in late postmenopausal women is a major determinant of osteoporosis,"
Journal of Bone and Mineral Research: The Official Journal of the American Society for Bone and Mineral Research, vol. 11, no. 3, pp. 337-349, 1996.

[55] K. Li, R. Kaaks, J. Linseisen, and S. Rohrmann, “Associations of dietary calcium intake and calcium supplementation with myocardial infarction and stroke risk and overall cardiovascular mortality in the Heidelberg cohort of the European Prospective Investigation into Cancer and Nutrition study (EPIC-Heidelberg)," Heart, vol. 98, no. 12, pp. 920-925, 2012.

[56] B. Abrahamsen and O. Sahota, "Do calcium plus vitamin D supplements increase cardiovascular risk?” BMJ, vol. 342, p. d2080, 2011.

[57] National Osteoporosis Society, Vitamin D and Bone Health: A Practical Clinical Guideline for Patient Management, NOS, London, UK, 2013.

[58] B. J. Gates, T. E. Sonnett, C. A. K. Duvall, and E. K. Dobbins, "Review of osteoporosis pharmacotherapy for geriatric patients," The American Journal of Geriatric Pharmacotherapy, vol. 7, no. 6, pp. 293-323, 2009.

[59] C. A. Inderjeeth and K. E. Poland, "Management of osteoporosis in older people," Journal of Pharmacy Practice and Research, vol. 40, no. 3, pp. 229-234, 2010.

[60] T. Coughlan and F. Dockery, "Osteoporosis and fracture risk in older people," Clinical Medicine, vol. 14, no. 2, pp. 187-191, 2014.

[61] J. A. Kanis, E. V. McCloskey, E. V. McCloskey et al., "European guidance for the diagnosis and management of osteoporosis in postmenopausal women," Osteoporosis International, vol. 24, no. 1, pp. 23-57, 2013.

[62] National Institute for Health and Care Excellence, Alendronate, -etidronate, Risedronate, Raloxifene and Strontium Ranelate for the -primary Prevention of Osteoporotic Fragility Fractures in Postmenopausal Women, Technology Appraisal Guide 160, NICE, London, UK, 2011.

[63] J. Pegrum, V. Dixit, N. Padhiar, and I. Nugent, "The pathophysiology, diagnosis, and management of foot stress fractures," The Physician and Sportsmedicine, vol. 42, no. 4, pp. 87-99, 2014.

[64] M. Fredericson, A. G. Bergman, K. L. Hoffman, and M. S. Dillingham, "Tibial stress reaction in runners," The American Journal of Sports Medicine, vol. 23, no. 4, pp. 472-481, 1995.

[65] E. Arendt, J. Agel, C. Heikes, and H. Griffiths, "Stress injuries to bone in college athletes," The American Journal of Sports Medicine, vol. 31, no. 6, pp. 959-968, 2003.

[66] A. Nattiv, G. Kennedy, M. T. Barrack et al., "Correlation of MRI grading of bone stress injuries with clinical risk factors and return to play," The American Journal of Sports Medicine, vol. 41, no. 8, pp. 1930-1941, 2013.

[67] J. Lassus, I. Tulikoura, Y. T. Konttinen, J. Salo, and S. Santavirta, "Bone stress injuries of the lower extremity," Acta Orthopaedica Scandinavica, vol. 73, no. 3, pp. 359-368, 2002.

[68] A. M. Groves, H. K. Cheow, K. K. Balan, B. A. Housden, P. W. P. Bearcroft, and A. K. Dixon, "16-Detector multislice CT in the detection of stress fractures: a comparison with skeletal scintigraphy," Clinical Radiology, vol. 60, no. 10, pp. 1100-1105, 2005.

[69] J. Pegrum, T. Crisp, N. Padhiar, and J. Flynn, "The pathophysiology, diagnosis, and management of stress fractures in postmenopausal women," The Physician and Sportsmedicine, vol. 40, no. 3, pp. 32-42, 2012. 
[70] C. C. Kaeding, J. R. Yu, R. Wright, A. Amendola, and K. P. Spindler, "Management and return to play of stress fractures," Clinical Journal of Sport Medicine, vol. 15, no. 6, pp. 442-447, 2005.

[71] K. E. Ensrud, S. K. Ewing, K. L. Stone, J. A. Cauley, P. J. Bowman, and S. R. Cummings, "Intentional and unintentional weight loss increase bone loss and hip fracture risk in older women," Journal of the American Geriatrics Society, vol. 51, no. 12, pp. 1740-1747, 2003.

[72] Z. Jaworski, M. Liskova-Kiar, and H. Uhthoff, "Effect of long-term immobilisation on the pattern of bone loss in older dogs," The Journal of Bone and Joint Surgery. British Volume, vol. 62-B, no. 1, pp. 104-110, 1980.

[73] G. Boivin and P. J. Meunier, "The mineralization of bone tissue: a forgotten dimension in osteoporosis research," OsteoporosInt, vol. 14, no. 3, pp. S19-S24, 2003.

[74] R. Recker, J. Lappe, K. M. Davies, and R. Heaney, "Bone remodeling increases substantially in the years after menopause and remains increased in older osteoporosis patients," Journal of Bone and Mineral Research, vol. 19, no. 10, pp. 1628-1633, 2004.

[75] M. P. Akhter, J. M. Lappe, K. M. Davies, and R. R. Recker, "Transmenopausal changes in the trabecular bone structure," Bone, vol. 41, no. 1, pp. 111-116, 2007.

[76] D. M. L. Cooper, C. D. L. Thomas, J. G. Clement, A. L. Turinsky, C. W. Sensen, and B. Hallgrímsson, "Agedependent change in the $3 \mathrm{D}$ structure of cortical porosity at the human femoral midshaft," Bone, vol. 40, no. 4, pp. 957-965, 2007.

[77] K. E. Schnackenburg, H. M. Macdonald, R. Ferber, J. P. Wiley, and S. K. Boyd, "Bone quality and muscle strength in female athletes with lower limb stress fractures," Medicine \& Science in Sports \& Exercise, vol. 43, no. 11, pp. 2110-2119, 2011.

[78] J. K. Yeh, C. C. Liu, and J. F. Aloia, "Effects of exercise and immobilization on bone formation and resorption in young rats," American Journal of Physiology-Endocrinology and Metabolism, vol. 264, no. 2, pp. E182-E189, 1993.

[79] R. T. Turner and N. H. Bell, "The effects of immobilization on bone histomorphometry in rats," Journal of Bone and Mineral Research: The Official Journal of the American Society for Bone and Mineral Research, vol. 1, no. 5, pp. 399407, 1986.

[80] A. D. LeBlanc, E. R. Spector, H. J. Evans et al., "Skeletal responses to space flight and the bed rest analog: a review," Journal of Musculoskeletal Neuronal Interactions, vol. 7, no. 1, pp. 33-47, 2007.

[81] C. Milgrom, M. Giladi, M. Stein et al., "Stress fractures in military recruits. A prospective study showing an unusually high incidence," The Journal of Bone and Joint Surgery. British Volume, vol. 67-B, no. 5, pp. 732-735, 1985.

[82] K. Khan, J. Brown, S. Way et al., "Overuse injuries in classical ballet," Sports Medicine, vol. 19, no. 5, pp. 341-357, 1995.

[83] D. R. Carter and W. C. Hayes, "Compact bone fatigue damage: a microscopic examination," Clinical Orthopaedics and Related Research, vol. 127, no. 127, pp. 265-274, 1977.

[84] P. Eichelberger, A. Blasimann, N. Lutz, F. Krause, and H. Baur, "A minimal markerset for three- dimensional foot function assessment: measuring navicular drop and drift under dynamic conditions," Eichelbergeretal. Journal of Foot and Ankle Research, vol. 11, p. 15, 2018.

[85] C. L. Brockett and G. J. Chapman, "Biomechanics of the ankle," Journal of Orthopaedic Trauma, vol. 30, no. 3, pp. 232-238, 2016.
[86] M. W. Cornwall and T. G. McPoil, "Relationship between static foot posture and foot mobility," Journal of Foot and Ankle Research, vol. 4, pp. 1-9, 2011.

[87] C. T. Rubin and L. E. Lanyon, "Regulation of bone formation by applied dynamic loads," Journal of Bone and Joint Surgery, vol. 66, no. 3, pp. 397-402, 1984.

[88] L. E. Lanyon and C. T. Rubin, "Static vs dynamic loads as an influence on bone remodelling," Journal of Biomechanics, vol. 17, no. 12, pp. 897-905, 1984.

[89] C. T. Rubin and L. E. Lanyon, "Regulation of bone mass by mechanical strain magnitude," Calcified Tissue International, vol. 37, no. 4, pp. 411-417, 1985.

[90] L. E. Lanyon, "Functional strain in bone tissue as an objective, and controlling stimulus for adaptive bone remodelling," Journal of Biomechanics, vol. 20, no. 11-12, pp. 1083-1093, 1987.

[91] K. M. Nicks, S. Amin, E. J. Atkinson, B. L. Riggs, L. J. Melton 3rd, and S. Khosla, "Relationship of age to bone microstructure independent of areal bone mineral density," Journal of Bone and Mineral Research, vol. 27, no. 3, pp. 637-644, 2012.

[92] R. A. Ross and A. Allsopp, "Stress fractures in royal marines recruits," Military Medicine, vol. 167, no. 7, pp. 560-565, 2002.

[93] R. P. Wilder and D. K. Brennan, "Physiological responses to deep water running in athletes," Sports Medicine, vol. 16, no. 6, pp. 374-380, 1993.

[94] R. P. Wilder, D. Brennan, and D. E. Schotte, "A standard measure for exercise prescription for aqua running," The American Journal of Sports Medicine, vol. 21, no. 1, pp. 45-48, 1993.

[95] A. Bitenc-Jasiejko, K. Konior, and D. Danuta Lietz-Kijak, "Meta-analysis of integrated therapeutic methods in noninvasive lower back pain therapy (LBP): The Role of Interdisciplinary Functional Diagnostics," Pain Research \& Management, vol. 2020, Article ID 3967414, 2020.

[96] M. J. Bolland and A. Grey, "Disparate outcomes from applying U.K. and U.S. osteoporosis treatment guidelines," The Journal of Clinical Endocrinology \& Metabolism, vol. 95, no. 4, pp. 1856-1860, 2010.

[97] G. S. Collins and K. Michaëlsson, "Fracture risk assessment: state of the art, methodologically unsound, or poorly reported?" Current Osteoporosis Reports, vol. 10, no. 3, pp. 199-207, 2012.

[98] M. J. Bridges and S. Ruddick, "Ability of FRAX/NOGG guidelines to identify patients sustaining low trauma fractures," Rheumatology (Oxford), vol. 49, pp. 391-392, 2011.

[99] S. S. Shariff, D. P. Baghla, C. Clark, and R. K. Dega, "Transient osteoporosis of the foot," British Journal of Hospital Medicine, vol. 70, no. 7, pp. 402-405, 2009.

[100] J. H. Wolf, "Julis Wolff and his "law of bone remodeling"” Orthopade, vol. 24, no. 5, pp. 378-386, 1995.

[101] R. L. Tomczak and R. VanCourt, "Metatarsal insufficiency fractures in previously undiagnosed osteoporosis patients," The Journal of Foot and Ankle Surgery, vol. 39, no. 3, pp. 174-183, 2000.

[102] C. De Laet, J. A. Kanis, A. Odén et al., "Body mass index as a predictor of fracture risk: a meta-analysis," Osteoporosis International, vol. 16, no. 11, pp. 1330-1338, 2005.

[103] P. Ravn, G. Cizza, N. H. Bjarnason et al., "Low body mass index is an important risk factor for low bone mass and increased bone loss in early postmenopausal women," Journal of Bone and Mineral Research, vol. 14, no. 9, pp. 1622-1627, 1999. 
[104] M. T. Barrack, J. C. Gibbs, M. J. De Souza et al., "Higher incidence of bone stress injuries with increasing female athlete triad-related risk factors," The American Journal of Sports Medicine, vol. 42, no. 4, pp. 949-958, 2014.

[105] A. Bitenc-Jasiejko, "Pedobarography as a diagnostic method for early detection of the risk of overload injuries within the sole in patients with diabetic foot syndrome," Wounds Treatment, vol. 14, no. 2, pp. 1-6, 2017.

[106] A. Bitenc-Jasiejko and M. Białas, "The scope of foot periodic and screening tests in the prevention of overload wounds and degeneration changes of the bones and joints of the foot-a pilot study," Wounds Treatment, vol. 15, no. 1, pp. 1-12, 2018.

[107] M. Brozgol, M. Arbiv, A. Mirelman, T. Herman, J. M. Hausdorff, and N. Vaisman, "Vertical ground reaction force during standing and walking: are they related to bone mineral density left-right asymmetries?" Gait \& Posture, vol. 54, pp. 174-177, 2017.

[108] J. E. Miller-Young, N. A. Duncan, and G. Baroud, "Material properties of the human calcaneal fat pad in compression: experiment and theory," Journal of Biomechanics, vol. 35, no. 12, pp. 1523-1531, 2002.

[109] B. D. Rooney and T. R. Derrick, "Joint contact loading in forefoot and rearfoot strike patterns during running," Journal of Biomechanics, vol. 46, no. 13, pp. 2201-2206, 2013.

[110] A. D. Leblanc, V. S. Schneider, H. J. Evans, D. A Engelbretson, and J. M Krebs, "Bone mineral loss and recovery after 17 weeks of bed rest," Journal of Bone and Mineral Research: The Official Journal of the American Society for Bone and Mineral Research, vol. 5, no. 8, pp. 843850, 1990.

[111] T. Lawson, A. Morrison, S. Blaxland, M. Wenman, C. G. Schmidt, and M. A. Hunt, "Laboratory-based measurement of standing balance in individuals with knee osteoarthritis: a systematic review," Clinical Biomechanics, vol. 30, no. 4, pp. 330-342, 2015.

[112] E. Geldhof, G. Cardon, I. De Bourdeaudhuij et al., "Static and dynamic standing balance: test-retest reliability and reference values in 9 to 10 year old children," European Journal of Pediatrics, vol. 165, no. 11, pp. 779-786, 2006.

[113] A. Skopljak, M. Muftic, A. Sukalo, and I. Masic, "Pedobarography in diagnosis and clinical application," Acta Informatica Medica, vol. 22, no. 6, pp. 374-378, 2014.

[114] Y. R. Choi, H. S. Lee, D. E. Kim et al., "The diagnostic value of pedobarography," Orthopedics, vol. 37, no. 12, pp. e1063-e1067, 2014.

[115] F. Scoppa, R. Capra, M. Gallamini, and R. Shiffer, "Clinical stabilometry standardization. Basic definitions-acquisition interval-sampling frequency," Gait \& Posture, vol. 37, pp. 290-292, 2013.

[116] F. Tamburella, G. Scivoletto, M. Iosa, and M. Molinari, "Reliability, validity, and effectiveness of center of pressure parameters in assessing stabilometric platform in subjects with incomplete spinal cord injury: a serial cross-sectional study," Journal of NeuroEngineering and Rehabilitation, vol. 11, no. 1, p. 86, 2014.

[117] B. R. Santos, A. Delisle, C. Larivière, A. Plamondon, and D. Imbeau, "Reliability of centre of pressure summary measures of postural steadiness in healthy young adults," Gait \& Posture, vol. 27, no. 3, pp. 408-415, 2008.

[118] L. D. Duffell, V. Gulati, D. F. L. Southgate, and A. H. McGregor, "Measuring body weight distribution during sit-to-stand in patients with early knee osteoarthritis," Gait \& Posture, vol. 38, 2013.
[119] K. Deschamps, G. A. Matricali, D. P. Desmet et al., "Efficacy measures associated to a plantar pressure based classification system in diabetic foot medicine," Gait \& Posture, vol. 49, pp. 168-175, 2016.

[120] L. Roosen and B. Wood, The Human Foot: A Companion to Medical Studies, Springer, Berlin, Germany, 2006.

[121] B. Najafi, R. T. Crews, D. G. Armstrong, L. C. Rogers, K. Aminian, and J. Wrobel, "Can we predict outcome of surgical reconstruction of Charcot neuroarthropathy by dynamic plantar pressure assessment?-A proof of concept study," Gait \& Posture, vol. 31, no. 1, pp. 87-92, 2010.

[122] W. B. Bell, "Further studies on the production of bovine hyperkeratosis by the administration of a lubricant," Virginia Journal of Science (New Series), vol. 3, pp. 169-177, 1952.

[123] M. J. Young, P. R. Cavanagh, G. Thomas, M. M. Johnson, H. Murray, and A. J. Boulton, "The effect of callus removal on dynamic plantar foot pressures in diabetic patients," Diabetic Medicine, vol. 9, no. 1, pp. 55-5, 1997.

[124] V. G. Patel and T. J. Wieman, "Effect of metatarsal head resection for diabetic foot ulcers on the dynamic plantar pressure distribution," The American Journal of Surgery, vol. 167, no. 3, pp. 297-301, 1994.

[125] A. Skopljak, A. Sukalo, O. BaticMujanovic, M. Becirevic, M. TiricCampara, and L. Zunic, "Assessment of diabetic polyneuropathy and plantar pressure in patients with diabetes mellitus in prevention of diabetic foot," Medical Archives, vol. 68, no. 6, pp. 389-439, 2014.

[126] A. J. M. Boulton, D. G. Armstrong, R. S. Kirsner et al., Diagnosis and Management of Diabetic Foot Complications, American Diabetes Association, Arlington, VA, USA, 2018.

[127] C. De Morais Barbosa, M. Barros Bértolo, J. F. Marques Neto, I. Bellini Coimbra, M. Davitt, and E. de Paiva Magalhães, "The effect of foot orthoses on balance, foot pain and disability in elderly women with osteoporosis: a randomized clinical trial," Rheumatology, vol. 52, no. 3, pp. 515-522, 2013.

[128] C. Volkering, S. Kriegelstein, S. Kessler, and M. Walther, "Behandlung von Rückfußdestruktionen beim Charcot-Fuß durch Hybridtechnik mit interner Osteosynthese und Ringfixateur," Operative Orthopädie und Traumatologie, vol. 27, no. 2, pp. 101-113, 2015.

[129] O.-Y. Kwon and M. J. Mueller, "Walking patterns used to reduce forefoot plantar pressures in people with diabetic neuropathies," Physical Therapy, vol. 81, no. 2, pp. 828-835, 2001.

[130] H. R. Ashry, L. A. Lavery, D. P. Murdoch, M. Frolich, and D. C. Lavery, "Effectiveness of diabetic insoles to reduce foot pressures," The Journal of Foot and Ankle Surgery, vol. 36, no. 4, pp. 268-271, 1997.

[131] J. Friedlein, J. Lorkowski, R. Wilk, and W. Hładki, "Charcot neuroarthropaty-etiology, diagnostic and treatment," Ostry Dyżur, vol. 8, no. 3, pp. 82-85, 2015.

[132] J. Tatoń, "Prophylactics of the diabetic foot syndrome based on pathophysiology," Medycyna Metaboliczna, vol. 18, no. 4, pp. 76-82, 2014. 